\title{
The experience of strengthening subsidence of the soil under the existing building in the city of Rostov-on-Don
}

\author{
Albert Prokopov ${ }^{1, *}$, Marina Prokopova ${ }^{2}$, Yana Rubtsova $^{2}$ \\ ${ }^{1}$ Don state technical University, Sotsialisticheskaya str, 162, Rostov-on-Don, 344022, Russia \\ ${ }^{2}$ Rostov state transport university, Rostovskogo Strelkovogo Polka Narodnogo Opolcheniya Sq., 2, \\ Rostov-on-Don, 344038, Russia
}

\begin{abstract}
Described problem for multi-storey residential development in the city of Rostov-on-Don on collapsible soils. The analysis of the technical and technological peculiarities of solidification under conditions of maintained buildings. Examples of projects of consolidation subsidence of foundation soils of buildings in operation 50-70 years.
\end{abstract}

\section{Formulation of the problem}

One of the essential problems of maintenance of buildings and facilities in the city of Rostov-on-Don is the presence of soil subsidence, which are the basis of many construction projects in different parts of the city.

Soil subsidence, which can not serve as a reliable basis buildings and structures are a serious problem for new construction, which can be solved in three directions:

- Extraction of soil subsidence at full power or a large part of the layer with laying the foundations under the soil subsidence and the organization of the underground part of the building used as underground parking, industrial floors, etc.;

- Design of pile foundations with a "recess" of the entire thickness of the soil subsidence and resting the heel of piles on unsettled ground;

- The elimination of the pre-construction properties of soils subsidence using soaking methods, mounting of ground piles, fixing by injecting compositions, reinforcement, etc.

This approach to design has been made possible thanks to the achievements in the study of the properties of soil subsidence, which were carried out in 60-80s. XX century prominent scientists E. Sergeev, V. Ananiev [1, 2], Y. Abelev [3], V. Krutov [4], E. Sorocan [5], Z. Ter-Martirosyan [6], Y. Gilman [7], V. Trofimov [8] and others.

However, the construction of Rostov-on-Don, formed in the XIX century, in the early and mid XX century, was designed without taking into account the properties of soil subsidence, using mostly strip foundations with a relatively small depth of laying on subsiding soils, which are in different power city areas varies from 1-2 to 12-15 meters or more.

${ }^{*}$ Corresponding author: prokopov72@rambler.ru 
Nowadays, residential buildings and facilities, which are operated 50-100 years or more, have a significant physical and moral wear and need major repairs or reconstruction. Manymulti-storey residential buildings that were built in the early and mid of XX century have significant defects in building constructions caused by differential settlement of foundation. A large number of residential buildings have steeply inclined cracks in loadbearing walls, typical for non-uniform base precipitated. The study of deformation allows us to select the most common reason for their appearance such as the local subsidence becoming soaked soil base, associated with technological leaks of water communications, filtration of surface water or groundwater level changes $[9,10]$.

Preservation of the existing housing stock requires a major overhaul, including a consolidation of foundation soil in order to improve their strength and deformation characteristics and eliminate sagging properties. Nowadays, the most common methods are fixing of soil subsidence by injecting solutions of differing composition, discharge pressure, types of used injectors, method of forming wells and distribution solutions and others.

\section{Solution to the problem}

Fixing of the foundation soil under existing buildings compared with new construction has a number of features, technical, technological and organizational difficulties related with the following factors:

- A significant change in soil properties under the sole foundation for the operation and the necessity for a detailed study during the execution of additional engineering and geological surveys, including tunnelling pits, sampling and testing of soil samples;

- You need to work in the conditions of use of the building, as a rule, without relocation of tenants;

- Tightness of the existing built-up areas;

- The large number of communications, requiring additional surveys and coordination of the project with the operating organizations, as well as impeding the uniform arrangement of CFA wells or injectors on the perimeter of the foundation;

- The presence of the design features of the building (additions, pits, stairs to the underground part, and others.), Complicating the scheme consolidate the foundation soil;

- Limiting the size and performance of the equipment used;

- Inaccessibility of certain areas of the base and foundation, for example, in the middle of the building without basement;

- The necessity of drilling and injection, with different levels (external - on the surface, internal - of cellars or collectors), which leads to the necessity of drilling holes of different depths and at different angles, the division of injections into levels (stope depth), application of injectors of various types and lengths, etc.;

- Risk of the lifting or deformation of the existing load-bearing structures of the building at a pressure of injection solutions in the foundation soil;

- The need for a tool for monitoring the position of bearing structures of the building in the process of fixing the base, and in the initial period (3-5 years) to further exploitation;

- The complexity of the quality control of the fixed base under the existing building as a result of die impossibility of tests to determine the main characteristics of controlled deformation modulus grouting.

Nevertheless, in the city of Rostov-on-Don developed many projects gain grounds under the existing buildings on the basis of different methods of grouting and soil reinforcement. Here are some examples of design solutions for specific buildings, designed in 2015 - 16 years under the Regional Program for the overhaul [11].

Example 1. Overhaul of an apartment building located at: Rostov-on-Don, Gerasimenko str., 7. 
The existing three-story residential building has a rectangular shape. Its dimensions in terms are 33,6 $\times 13,8 \mathrm{~m}$. Basement is located under the whole building, basement height is 2.3-2.9 m. The building has a strip foundation made of rubble stone. Depth of laying the foundation of 3.2-3.6 meters. The structural scheme of the building is a frameless. The walls are made of bricks. The building was built in 1956. The building relate to the II (normal) level of responsibility. Based on the survey base and supporting structures, made in August 2016, the state bearing structures of the building was found in an emergency [12] .The main causes of damage to building structures are irregular rainfall soil base of the building, caused by the leakage of their soaking water communications, and atmospheric waters. When drilling in August 2016 to a depth of $12.0 \mathrm{~m}$ groundwater is not opened [13].

Specific primers on site are bulk and subsidence (GTE-1). Bulk soil is loam soil mixed with debris, spread to a depth of $0.3-1.4 \mathrm{~m}$, and fully "erupt" foundations. The soils of GTE-1 have sagging properties to a depth of $6.5-7.3 \mathrm{~m}$. Ground subsidence conditions relate to the first type. The natural base for foundations are subsiding loam is EGE-1.

To eliminate sagging properties of soil base and increase its deformation module provides consolidation of foundation soil by the method of reinforcement by elements of high rigidity with soil grouting (RF patent №2103441 [14]).

Project foresees drilling diameter 70-80 mm, length $5 \mathrm{~m}$ and 7.5 established following sequence of work be performed initially drilling and injection solution in vertical wells, contouring fixing zone, and then the drilling and injection solution in deviated wells intersecting or skew directly under the sole strip foundations (Fig. 1). Drilling of wells provided both from the surface and out of the basement around the perimeter of the outer contours of the building and inner longitudinal load-bearing wall.

Strength indicators of the fixed base are regulated by the amount of charge in the borehole binder (cement-sand mortar).Deformation module of the reinforced base is assigned equal to $21 \mathrm{MPa}$ in terms of reduction in average rainfall of the base and the relative difference between pellet with the full water saturation to an acceptable level. [15]

Example 2. Overhaul of an apartment building located at: Rostov-on-Don, Lenina str., $109 / 1$.

The building is a residential 5-storey large-block building with four-access, without a basement. In terms of building a rectangular configuration with dimensions on the outer contour of $68,3 \times 12,5 \mathrm{~m}$. Under building along the central supporting wall runs the collector, which houses water-bearing and low-voltage communications. Strip foundations prefabricated foundation blocks of monolithic reinforced concrete belt.

The liability of the buildings - II (normal).

In August 2016 when drilling wells to a depth of $18.00 \mathrm{~m}$ groundwater established at depths of 5.00-5.40 (abs. Elevation. 47,70-47,00 m) [16]. Unconfined aquifer. According to regional data, seasonal fluctuations in the level of groundwater is $1.0-1.5 \mathrm{~m}$.

The waters have sulphate aggression to concrete of ordinary grades of cement.

Specific soils at the site include:

- Bulk soils: loamy soil mixed with debris; Distribution layer range from 0.0 to 1.20 $1.90 \mathrm{~m}$.

- Soil subsidence - EGE-1 - loam heavy, dusty, tight plastic, pro-sedimentary, nonsaline. The interval of the spread layer is $1.20-1.90 \mathrm{~m}$ to $3,50-4,10 \mathrm{~m}$.

The grounds of the building foundations are subsiding loam is EGE-1.

Type of soil conditions for subsidence - I.

According to the results of visual inspection of the building marked deformation in the form of cracks. A survey of foundations and supporting structures of the building, their technical condition assessed as limited usable, requiring major repairs, including consolidation of foundation soil [17]. 


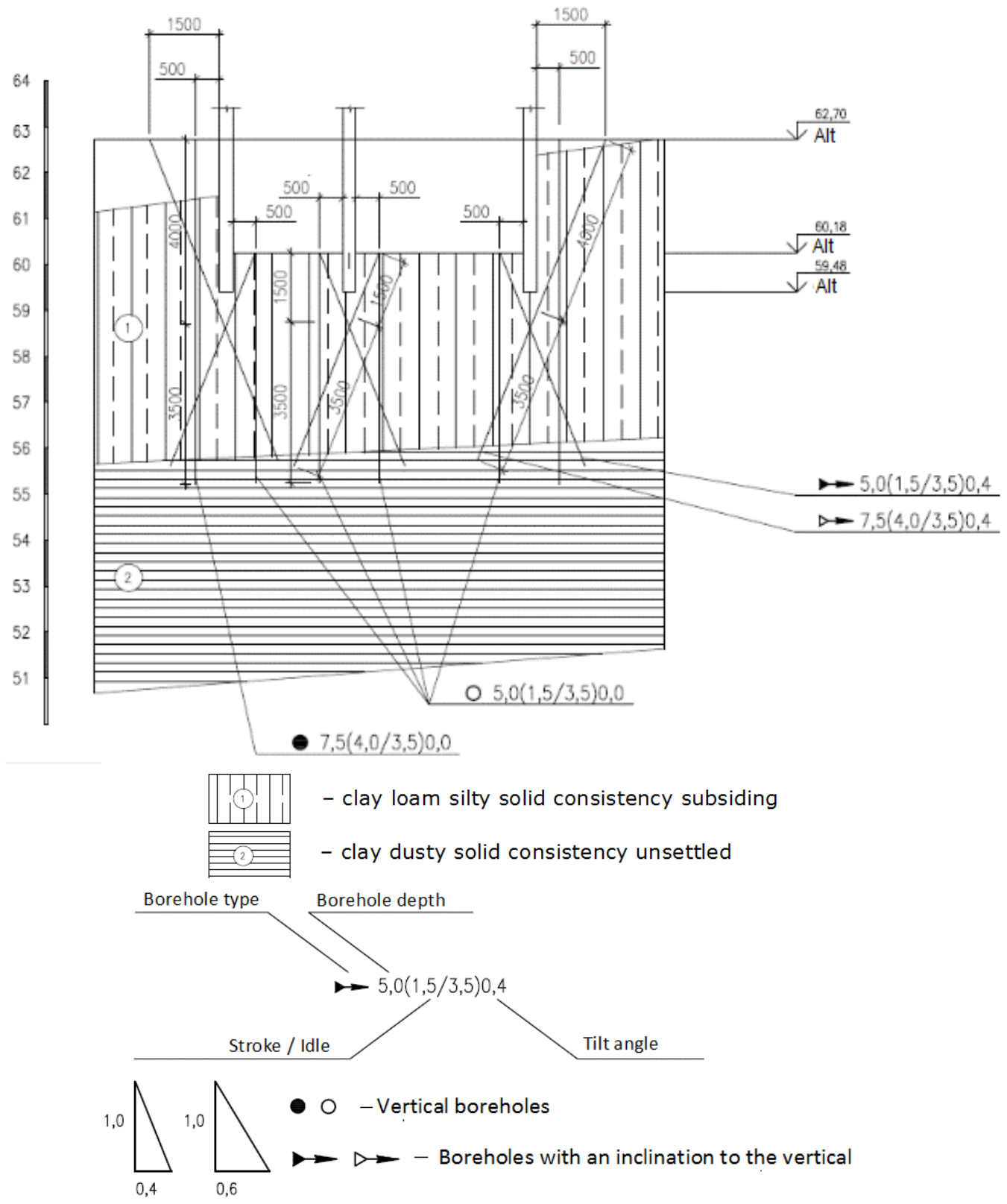

Fig. 1. Diagram of fixing subsiding soil dwelling house foundation at:

Rostov-on-Don, st. Gerasimenko, 7 by the reinforcement elements of high rigidity using soil grouting

The main difficulty in the development of the project began to fix subsidence lack of a building basement and the inability to drill injection wells inside the foundations of external load-bearing walls. In this regard, it was decided to drill wells with a reduced pitch with the surface of the outer contour of the building, as well as the CFA wells from the reservoir. To be able to mount the drilling rig and drilling directional wells from a reservoir, in its sole device is provided inclined trench technology. The project [18] provides for reinforcement of soil base increased rigidity elements using the method of cementation of soil to a depth 
of $2.6 \mathrm{~m}$ below the base of the foundations of a recess entire subsidence column. Works are provided in one step depth (Fig. 2).

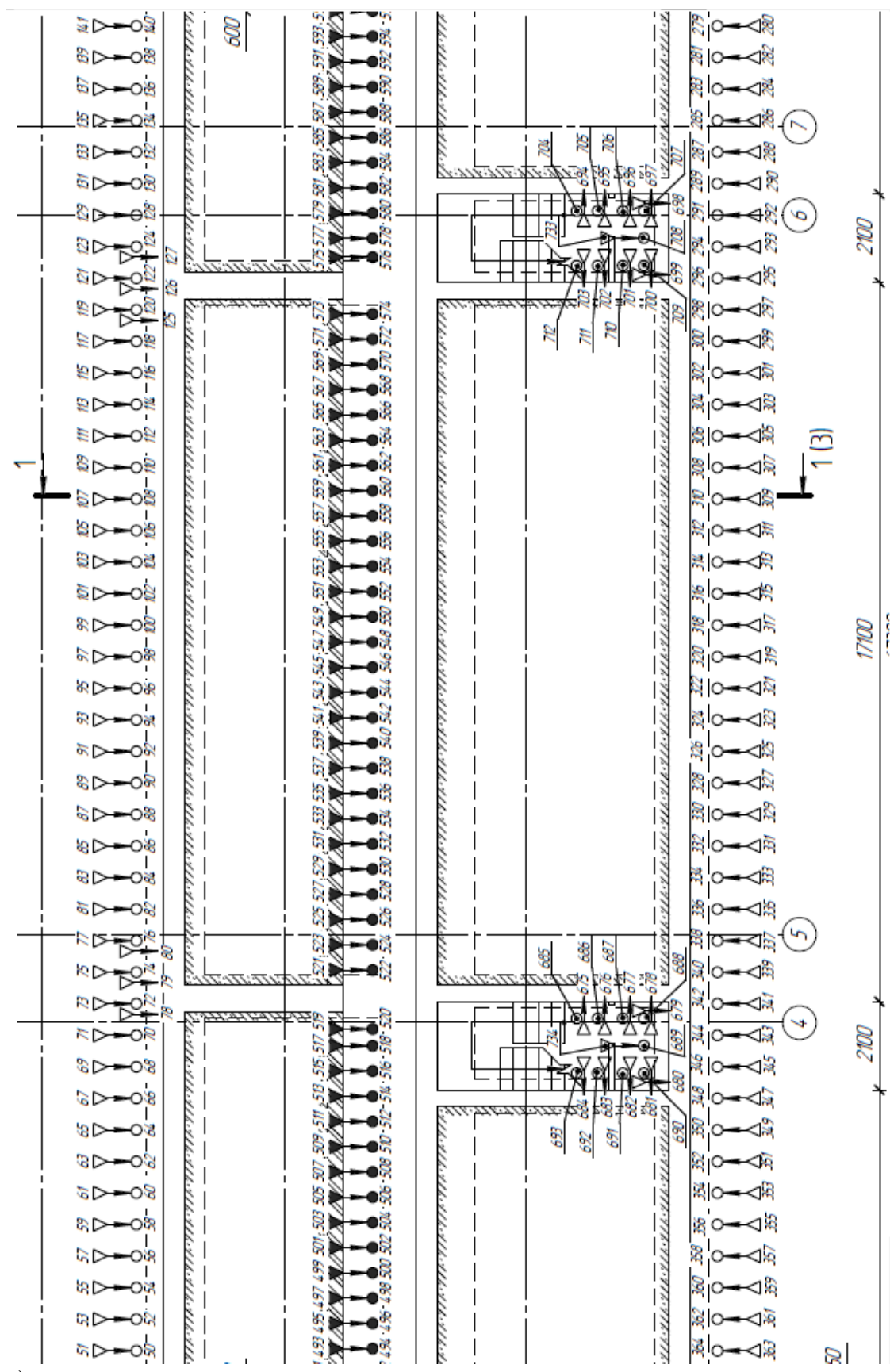

a) 


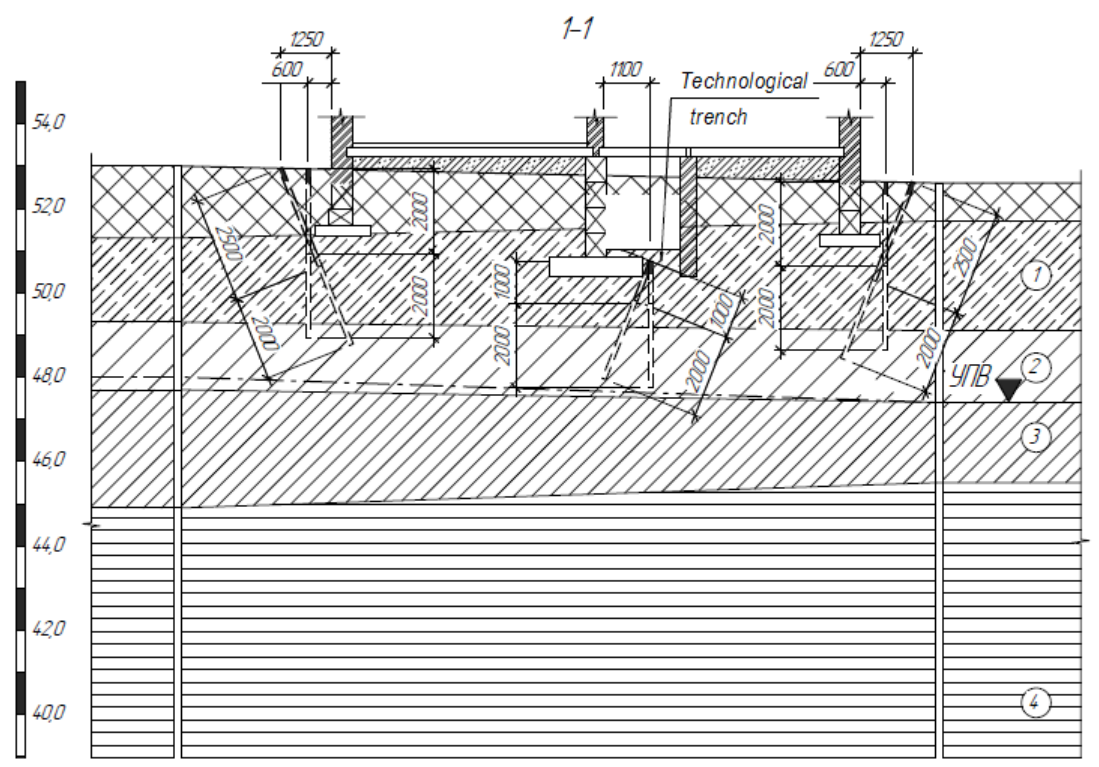

b)

Fig. 2. a-b) Scheme of secure area subsiding soil base of a residential building located at: Rostov-onDon, Lenin str., 190/1 (shown fixing section of the 2nd section house in axes 4-7, securing the rest of the grounds of sections produced in a similar way)

Work technology involves drilling and injecting them into the cement-sand mortar. Injections are performed with the basic steps of $0.6 \mathrm{~m}$ for the inner walls and $0.75 \mathrm{~m}-$ for the exterior.

After fixing the base of the building foundations should be a homogeneous mass of soil reinforced with rigid inclusions from the cement stone, which will provide no additional deformations in the case of soaking. Composition of the mixture injected - cement-sandwater $=1: 3: 2$ (by weight). To prepare the solution used Portland cement sulphate according to GOST 22266-2013.

Example 3: Overhaul of an apartment building located at: Rostov-on-Don, Krasnoarmeyskaya str, 103/123. Liter B.

The building of an apartment building is a four-story building, consisting of three blocks separated by expansion joints, arranged in a square, forming a closed space of the yard, with a cellar under part of the building and a single-storey block located in the courtyard.

The building was built in 1937. Level of responsibility - II (normal).

Measures to strengthen the structures and grounds of foundation base are carried out on the base letter "B", subjected to the greatest deformation due to soaking soil base of the foundations in place of the heating duct entry and placement of a heating substation building. Overall dimensions of the building block (letter "B") constitute 13,4 × 45,2 m. Heights above ground floors are $3.7 \mathrm{~m}$, basement is $2.16 \mathrm{~m}$.

The geological and lithological cross-sectional area to a depth of $20.0 \mathrm{~m}$ according to drilling, from top to bottom are highlighted:

- Bulk soil (tQ $\mathrm{tV}_{\mathrm{IV}}$ ) is black and brown loam semi-solid, with inclusions of debris. It extends to a depth of $0.8-1.7 \mathrm{~m}$. An element is not selected as the engineering-geological.

- EGE-1 (dQ $\mathrm{dII})$ - Upper light brown, brown loam heavy, dusty, hard, subsidence, water saturation at soft-plasticity, non-saline; 
- GTE-2 (dQ $\mathrm{dIIIII}_{\text {- }}$ - loam heavy, dusty, tight-plasticity, unsettled, in the aeration zone of non-saline;

- IGE-2a ( $\left.\mathrm{dQ}_{\mathrm{II}-\mathrm{III}}\right)$ - loam heavy, dusty, soft-plastic, unsettled.

Specific soils are dry bulk and soil subsidence. Bulk soil is cut at full capacity, with a depth of laying the foundation of $2.5 \mathrm{~m}$. Subsiding soils spread with a depth of $0.8-1.7 \mathrm{~m}$ to 5.0 $5.5 \mathrm{~m}$.Power subsidence thickness is 3,3-4,5 $\mathrm{m}$. The land subsidence under its own weight when the soil is soaked 1,85-2 $83 \mathrm{~m}$. Type of ground subsidence conditions -I. Groundwater at the time of survey (July 2013) revealed at a depth of 6.7-7.5 m amplitude of seasonal fluctuations of $0.7-1.0 \mathrm{~m}$.

The structural scheme of the building - frameless. The main load-bearing elements are longitudinal and transverse brick walls. Above the basement and on the through passage is made of monolithic reinforced concrete on a brick filler for steel beams.

The foundations of the walls -strip, rubble concrete, made of but-sandstone $-670 \mathrm{~mm}$ thick, shallow. The width of the sole foundations exterior walls $1.27 \mathrm{~m}$, internal $-1.47 \mathrm{~m}$ Foundations do not possess sufficient rigidity due to differential settlement of the foundation soil.

In the operation of the building because of poor operation of water-bearing systems and multiple strains of the blind area of foundation soils subjected to becoming soaked, and as a result, subsidence. The brick walls of the building are formed multiple vertical and inclined crack width opening ot 1,0 to $20.0 \mathrm{~mm}$, the distortion of window frames and doors, as well as the deviation from the vertical wall, caused by irregular rainfall foundation soil [19].

To eliminate the manifestations of subsidence properties, reducing sediment unevenness and improve the bearing capacity of soils developed a draft overhaul of the building [20], providing for their consolidation method cement and ground reinforcements in accordance with the provisions of section 6.2 TSN 50-306-2005 [21]. This is achieved by drilling wells of leader $\varnothing 40 \mathrm{~mm}$ and immersing them in injectors $\varnothing 32 \times 3$ and discharge them cementsoil pressure 3,6 atm. After solidification of the solution is formed uniform in its physical and mechanical properties of the soil directly into the array based foundations (Fig. 3).

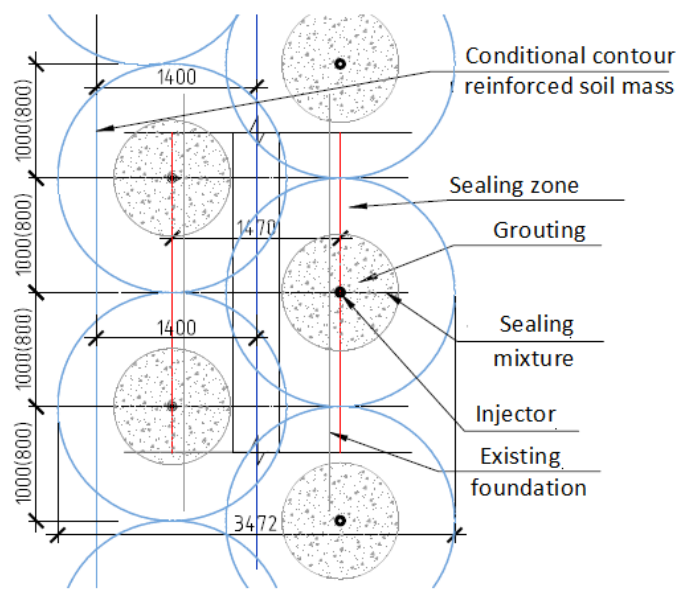

Fig. 3. The scheme of formation of the reinforced base

The height of the reinforced base received $3.13 \mathrm{~m}$ below the foundation base. The reinforcing elements are arranged with a pitch of $1.0(0.8) \mathrm{m}$ on all axes in all building area. The volume of the reinforcing elements is $5 \%$ of the total of the reconstructed ground. The strength of cement-stone ground reinforcing elements uniaxial compression at $20 \%$ of the cement content in the solution adopted by $1.15 \mathrm{MPa}$. 


\section{Conclusions}

Residential multi-storey buildings in Rostov-on-Don, designed in the early - mid XX century, is mostlyhave strip foundations of rubble or masonry, grounds which are subsiding soils of different capacities.

As a result, long-term operation will inevitably arise becoming soaked soils, caused by both natural and man-made causes. As a result of becoming soaked arose subsidence and deformation of soil and supporting structures of the building. Inspection of the technical condition of many residential buildings in operation for more than 50 years, set an alarm or restricted operating state of soil bases and foundations.

It is currently under development and implementation of massive overhaul project of multi-storey buildings located in different parts of the city of Rostov-on-Don, including strengthening the foundation soils and foundation of the Program [11].

Currently, the most widely used methods for strengthening of soil subsidence, based on injected into the soil reinforcement solutions and the formation of the reinforcing elements in the soil. The main differences in the methods used are as well placement schemes, types of used injectors, injection pressure and the formation of the reinforcing elements.

\section{References}

1. V. Ananiev Moscow, Foreign Jurisprudence (2012).

2. V. Ananiev Proceedings of the Rostov State University of Civil Engineering.15.(2011).

3. Y. Abelev, M. Abelev Basics of designing and constructing on subsiding macroporous soils, Stroyizdat, Moscow, 271, (1979)

4. V. Krutov Foundations on subsiding soils, Kiev, (1982).

5. M. Sokolov, V. Krutov, E. Sorochan The construction of large buildings on collapsible soils. Stroyizdat, Moscow, (1965)

6. Z. Ter-Martirosyan, Rheological parameters of soils and structures calculations bases. Stroyizdat, Moscow, (1990)

7. J. Gilman Foundations in loess subsiding soils. Rostov-on-Don, (1991)

8. 8.V. Trofimov The genesis of subsidence of loess soils. Moscow State University, Moscow (1999)

9. M. Prokopova, G. Lukyanova "Building 2011": Matt. Intern. scientific-prac. Conf. Rostov-on-Don, Rostov State University of Civil Engineering, P. 137 - 138, (2011)

10. A. Prokopov, V. Zhur, Y. Rubtsova, Sergeevs reading. Engineering geology and geoecology. Fundamental problems and applied problems, People's Friendship University, Moscow, 18, (2016)

11. Resolution of the Government of the Rostov region of 26.12.2013,803 «On approval of the Regional Programme for the overhaul of the common property in multifamily housing in the Rostov region for 2015 - 2049 years"

12. Report on the results of the survey on the project: "Overhaul of apartment buildings on the street №7. Gerasimenko in Rostov-on-Don ", LTD "GeoIndustriya" Rostov-onDon, (2016)

13. A technical report on the results of geological engineering survey on the project: "Overhaul of apartment buildings on the street №7. Gerasimenko in Rostov-on-Don ", LTD "GeoIndustriya", Rostov-on-Don, (2016)

14. A. Golovanov, V. Pashkov, V. Sergeev, A method of fixing the soil, Patent 2103441, (1998) 
15. Enhancing soils of foundations and supporting structures for the project: Apartment house on the street. Gerasimenko, 7 in Rostov-on-Don. Project documentation. LTD "GeoIndustriya", Rostov-on-Don, PN: 3U-ZG-KR, (2016)

16. A technical report on the results of geological engineering surveys for preparation of project documentation "Residential building located at: Rostov-on-Don, pr. Lenin, 109/1 ", LLC "Geotechnics-block-Service", Rostov-on-Don, (2016)

17. Technical report of building structures "Residential building located at: Rostov-onDon, Prospekt Lenina, 109/1", LLC "Geotechnics-block-Service", Rostov-on-Don, (2016)

18. Production of project documentation for the strengthening of soils of foundations and supporting., LTD "Geotechnics-Block Service", Rostov-on-Don, PN: 6U / 2016 HS. (2016)

19. A technical report on the results of engineering surveys for preparation of project documentation for the project: "Overhaul of apartment buildings №103 / 123, letter" $B$ "on the street. Red Army in the city of Rostov-on-Don ", LTD "South Construction Company" Rostov-on-Don, (2016)

20. Overhaul of the apartment building №103 / 123, Project documentation. , LLC "Construction Company of South", Rostov-on-Don, 07-0816-CD. (2016)

21. Foundations Extra Load, Rostov-on-Don, Russian standart 50-306-2005 (2005) 